\title{
Effect of PWHT on properties of 485MPa tensile strength vessel steel
}

\author{
Zhao Xinyu ${ }^{1,2, a}$, Zou Yang ${ }^{1,2}$, Qin Liye ${ }^{1,2}$ and Liu Yang ${ }^{1,2}$ \\ ${ }^{1}$ Plate Technology, Shougang Research Institute of Technology, 100083 Beijing, China \\ ${ }^{2}$ Beijing key Laboratory of Green Recyclable Process for Iron \& steel Production Technology, 100083 Beijing, China
}

\begin{abstract}
Effect of Post-Welding Heat Treatment (PWHT) on properties of 485MPa tensile strength vessel steel was studied by changing carbon contents and parameters of heat treatment. The conclusions are: The strengths of vessel steel decrease after PWHT. And the amounts of strength reduction increase with the carbon contents rising. To get the tensile strength $\geq 485 \mathrm{MPa}$ vessel plates, of given $\mathrm{Mn}$ content $1.45 \%$, the carbon content is designed over $0.17 \%$ in case of $900^{\circ} \mathrm{C}$ normalization, over $0.20 \%$ in case of $620^{\circ} \mathrm{C}$ holding temperature in 2 hours, over $0.23 \%$ in case of $620^{\circ} \mathrm{C}$ holding temperature in 2 hours by 3 times, and over $0.20 \%$ in case of $620^{\circ} \mathrm{C}$ holding temperature in 6 hours. The impact toughness are decreased by PWHT at all carbon contents. The SEM images of morphology of microstructure are studied to research on mechanism of strength reduction by PWHT. Then it's found that the pearlites are broken and cementite phases precipitate along grain boundary along with the process of PWHT, which brings about a reduction of strength.
\end{abstract}

\section{Instruction}

Post-Welding Heat Treatment (PWHT) is a heat treatment method in order to improve the mechanical property and structure and relief the residual stress of welding joint, which is kind of stress relief annealing. A part or component is heated to a special temperature with a special heating rate and maintained to be a fixed time and then cooled in furnace with very low cooling rate. An amount of reports had been published about the research on effect on mechanical property of PWHT through simulating method in Lab ${ }^{[1]-[6]}$. But it is rarely reported that effect of PWHT on properties of vessel steel with various carbon content and many times recycles.

Based on 485MPa tensile strength vessel steel, effect of carbon contents and thermal recycles times on properties is studied to research on mechanism of strength reduction by PWHT.

\section{Experimental}

The chemical compositions of samples are presented in Table 1.

Table 1. Chemical composition (in mass \%).

\begin{tabular}{|c|c|c|c|c|c|c|}
\hline & $\mathrm{C}$ & $\mathrm{Si}$ & $\mathrm{Mn}$ & $\mathrm{P}$ & $\mathrm{S}$ & Alt \\
\hline $\begin{array}{c}\text { Steel } \\
\text { A }\end{array}$ & 0.13 & 0.37 & 1.44 & 0.009 & 0.003 & 0.034 \\
\hline $\begin{array}{c}\text { Steel } \\
\text { B }\end{array}$ & 0.17 & 0.35 & 1.44 & 0.009 & 0.002 & 0.034 \\
\hline $\begin{array}{c}\text { Steel } \\
\text { C }\end{array}$ & 0.20 & 0.24 & 1.46 & 0.006 & 0.003 & 0.016 \\
\hline
\end{tabular}

\begin{tabular}{|c|c|c|c|c|c|c|}
\hline $\begin{array}{c}\text { Steel } \\
\mathrm{D}\end{array}$ & 0.23 & 0.31 & 1.46 & 0.006 & 0.003 & 0.017 \\
\hline $\begin{array}{c}\text { Steel } \\
\mathrm{E}\end{array}$ & 0.25 & 0.24 & 1.47 & 0.005 & 0.003 & 0.013 \\
\hline
\end{tabular}

The dimensions of ingots are $125 \mathrm{~mm}$ (Thickness) $* 130 \mathrm{~mm}$ ( Width ) $* 270 \mathrm{~mm}$ ( Length). And the plate's thickness after rolling are $20 \mathrm{~mm}$.

All the samples were normalized at temperature $900^{\circ} \mathrm{C}$. After that some samples were simulated to PWHT. The detail parameters of PWHT and heat treatment are presented in Table 2. Every samples are identified by abbreviation in column "Samples" of table.

Table 2. Parameters of PWHT and heat treatment

\begin{tabular}{|c|c|c|c|c|}
\hline Samples & $\begin{array}{c}\text { Temp } \\
\text { e- } \\
\text { rature }\end{array}$ & $\begin{array}{c}\text { Heat } \\
\text { Treatment } \\
\text { Process }\end{array}$ & $\begin{array}{c}\text { Holding } \\
\text { Time }\end{array}$ & $\begin{array}{c}\text { Thermal } \\
\text { Cycle } \\
\text { Times }\end{array}$ \\
\hline $900 \mathrm{~N}$ & $900^{\circ} \mathrm{C}$ & Normalization & $40 \mathrm{~min}$ & - \\
\hline $620-2$ & $620^{\circ} \mathrm{C}$ & PWHT & $2 \mathrm{~h}$ & One time \\
\hline $620-2-2$ & $620^{\circ} \mathrm{C}$ & PWHT & $2 \mathrm{~h}$ & Two times \\
\hline $620-2-2-2$ & $620^{\circ} \mathrm{C}$ & PWHT & $2 \mathrm{~h}$ & Three times \\
\hline $620-6$ & $620^{\circ} \mathrm{C}$ & PWHT & $6 \mathrm{~h}$ & One time \\
\hline
\end{tabular}

\section{Results and Discussion}

\subsection{Effect on strength of PWHT}

Effects on tensile strength of PWHT with various carbon contents are shown in Fig. 1. The criterion of yield 
strength of this vessel steel is $260 \mathrm{MPa}$ and the criterion of tensile strength is $485 \mathrm{MPa}$. As shown in figure, the yield strengths decrease sharply after PWHT with holding time rising and thermal cycle times. Furthermore the yield strengths increase with carbon contents rising. But all the yield strengths are larger than yield criterion. However the tensile strengths drop obviously after PWHT with holding time rising and thermal cycle times. The tensile strengths increase with carbon contents rising.

To get the tensile strength $\geq 485 \mathrm{MPa}$ vessel plates, of given $\mathrm{Mn}$ content $1.45 \%$, the carbon content is designed over $0.17 \%$ in case of $900^{\circ} \mathrm{C}$ normalization, over $0.20 \%$ in case of $620^{\circ} \mathrm{C}$ holding temperature in 2 hours, over $0.23 \%$ in case of $620^{\circ} \mathrm{C}$ holding temperature in 2 hours by 3 times, and over $0.20 \%$ in case of $620^{\circ} \mathrm{C}$ holding temperature in 6 hours. It's obviously that strength reduction with many times cycles is larger than that with single cycle in case of same total holding time.
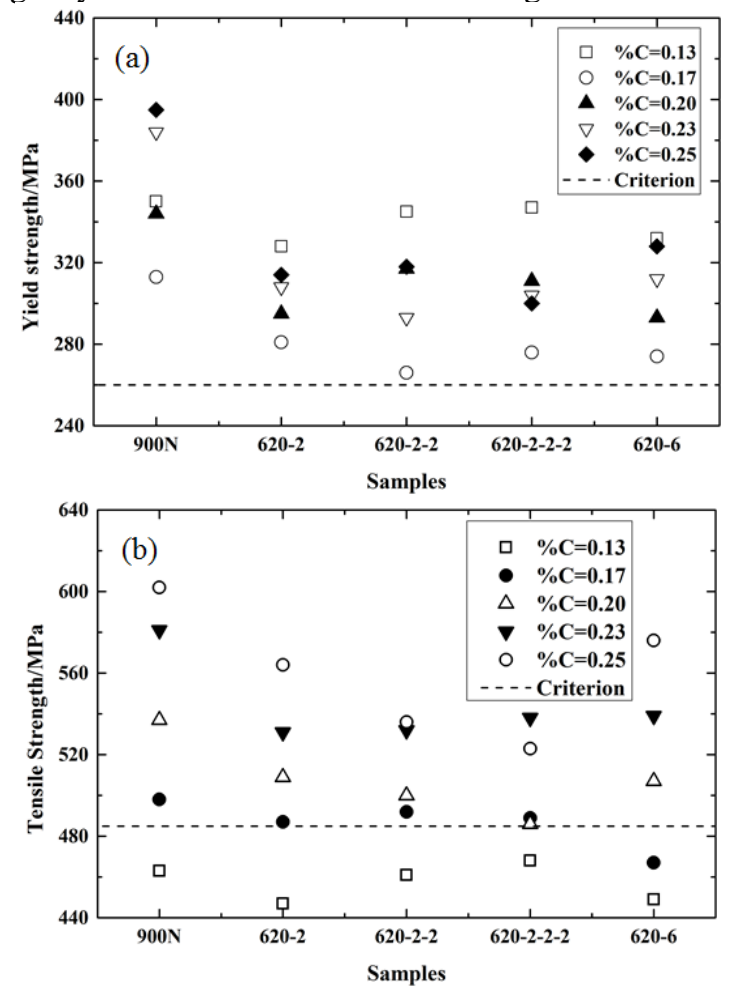

Fig.1 Effect on tensile properties of PWHT: (a) Effect on yield strength of PWHT and (b) effect on tensile strength of PWHT

\subsection{Effect on impact toughness of PWHT}

Effects on impact toughness of PWHT are shown in Fig.2. And the test temperatures are $-20^{\circ} \mathrm{Cand}-40^{\circ} \mathrm{C}$ respectively.
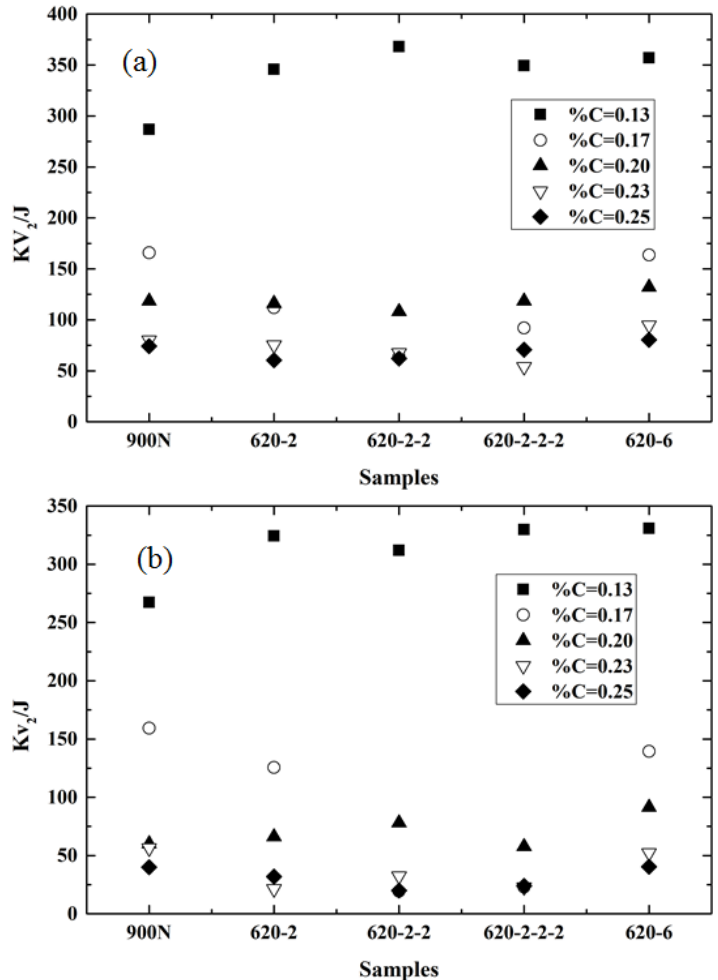

Fig.2 Effect on impact toughness of PWHT: (a) impact temperature $-20^{\circ} \mathrm{C}$ and (b) impact temperature $-40^{\circ} \mathrm{C}$

The impact toughness decrease slightly after PWHT. And the impact toughness decrease sharply with carbon contents rising. The impact energies are greater than $250 \mathrm{~J}$ if carbon content is $0.13 \%$. But impact energies decrease obvious in case of carbon contents rising.

\subsection{Effect on microstructure of PWHT}

SEM observations are taken to research on effect of PWHT on microstructure for steel E with $0.25 \%$ carbon content, as shown in Fig. 3. The pearlites of samples after normalizing are fine and intact lamellar structure (Fig. 3 (a)). But some lamellar pearlites of samples are broken after PWHT with 2 hours holding time and transform to columnar structure (Fig. 3 (b)). Moreover more lamellar pearlites of samples of many thermal cycle times of PWHT are broken and more and more precipitated $\mathrm{Fe} 3 \mathrm{C}$ precipitate along with grain boundary (Fig. 3 (c) (d)). 

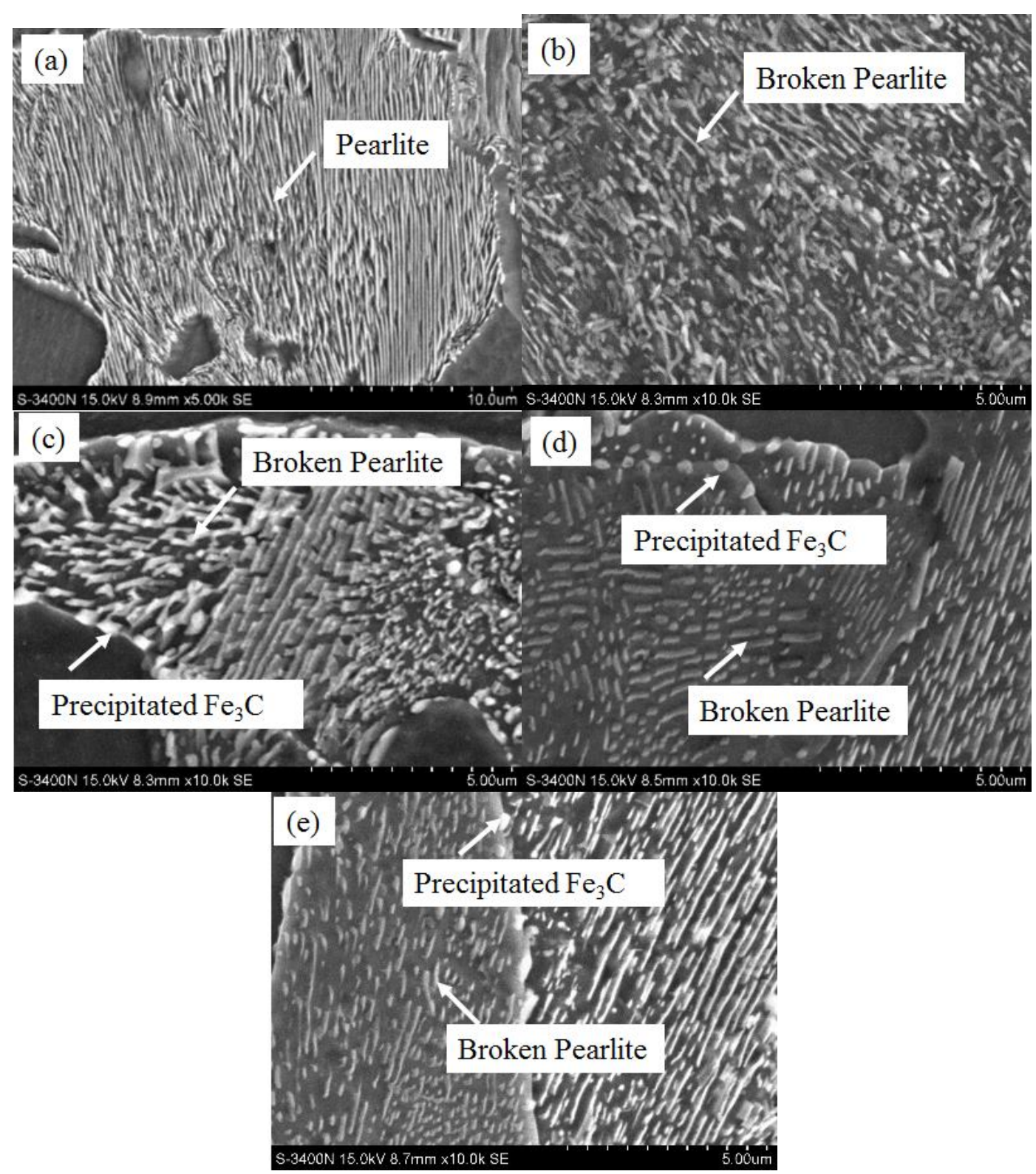

Fig.3 SEM images of morphology of Pearlite of steel E (mass w(C)=0.25\%): (a) 900N (b) 620-2 (c) 620-2-2 (d) 620-2-2-2 (e) 620-6

Comparing Fig. 3 (d) with Fig. 3 (e), the pearlites of samples after 2 hours by 3 times cycles are broken severely and more precipitated $\mathrm{Fe} 3 \mathrm{C}$ than that after 6 hours. That is the reason that strength reduction with many times cycles is larger than that with single cycle in case of same total holding time.

The pearlite lath spacing on center location of samples are measure by SEM. And the statistics are taken no less than 100 pearlites lath on 10 photos each sample. The results are shown in Fig. 4. The lath spacing are among $0.19 \sim 0.30 \mu \mathrm{m}$. Moreover there are no significant change in different parameters of samples.

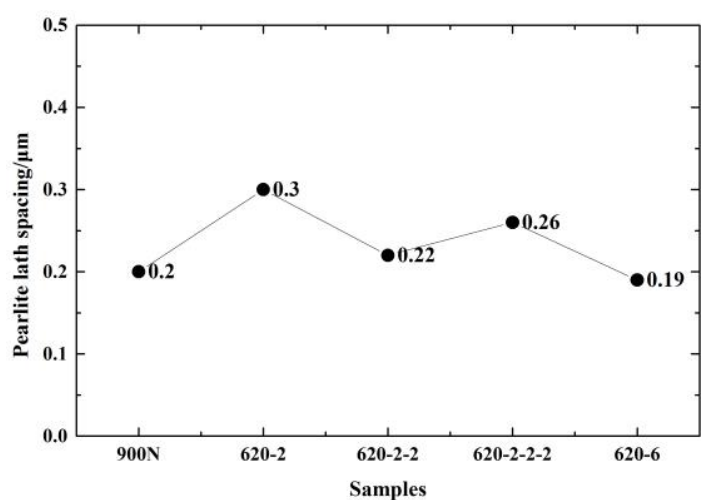

Fig.4 Effect on pearlite lath spacing of PWHT

Diagrammatic sketch of effect on pearlite structure of PWHT is shown in Fig.5. A mechanism of strength reduction induced by PWHT is drawn. Firstly the pearlites of normalizing samples are lamellar structure. Secondly the pearlites of PWHT with 2 hours holding time are broken by PWHT, which induces strength 
reduction. Finally the pearlites of PWHT with 6 hours holding time are broken severely and some precipitated $\mathrm{Fe} 3 \mathrm{C}$ precipitate, which induces further strength reduction.

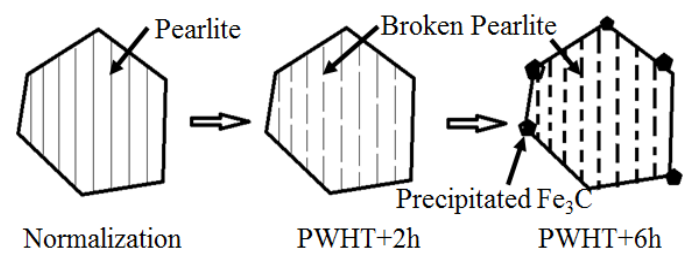

Fig. 5 Diagrammatic sketch of effect on pearlite structure of PWHT

\section{Conclusions}

Effect of PWHT on properties of $485 \mathrm{MPa}$ tensile strength vessel steel was researched by changing carbon contents and parameters of heat treatment. The following conclusions are drawing:

1. The tensile strengths drop obviously after PWHT with holding time rising and thermal cycle times. The tensile strengths increase with carbon contents rising.

2 . To get the tensile strength $\geq 485 \mathrm{MPa}$ vessel plates, of given $\mathrm{Mn}$ content $1.45 \%$, the carbon content is designed over $0.17 \%$ in case of $900^{\circ} \mathrm{C}$ normalization, over $0.20 \%$ in case of $620^{\circ} \mathrm{C}$ holding temperature in 2 hours, over $0.23 \%$ in case of $620^{\circ} \mathrm{C}$ holding temperature in 2 hours by 3 times, and over $0.20 \%$ in case of $620^{\circ} \mathrm{C}$ holding temperature in 6 hours. And strength reduction with many times cycles is larger than that with single cycle in case of same total holding time

3. The impact toughness decrease slightly after PWHT. And the impact toughness decrease sharply with carbon contents rising.

4. Firstly the pearlites of normalizing samples are lamellar structure. Secondly the pearlites of PWHT with 2 hours holding time are broken by PWHT, which induces strength reduction. Finally the pearlites of PWHT with 6 hours holding time are broken severely and some precipitated $\mathrm{Fe} 3 \mathrm{C}$ precipitate, which induces further strength reduction.

\section{References}

1. Wang J, Lu H, Murakawa H. Transactions of JWRI, 27(1998)

2. Guozheng Zhang, Feng Zhao. Industrial heating, 1 (2013)

3. Ravi S, Balasubramanian $\mathrm{V}$, Nasser $\mathrm{S} \mathrm{N}$. Inter. journal of fatigue, 27 (2005)

4. Mitchell D R G, Moss C J, Griffiths R R. Inter. J. pressure vessels and piping, , 76(1999)

5. Wang Z, Chen W. Petro-Chemical Equipment, 1(2010)

6. Stout R D. Weld. Res. Counc. Bull., 30 (1985) 